\title{
APPLICATION OF CASE TEACHING TECHNIQUE IN EDUCATIONAL PROCESS
}

\author{
Manuela Tvaronavičienė, Romualdas Ginevičius \\ Vilnius Gediminas Technical University, Sauletekio al. 11, LT-2040 Vilnius, Lithuania, \\ e-mail: manuela@post.omnitel.net ${ }^{1}$,rector@adm.vtu.lt ${ }^{2}$
}

Received 8 April, 2003

\begin{abstract}
In the article a case study method, which is amply used at Harvard Business School in United State of America and also at European Business Schools characterized by top ratings, has been analyzed. A case study method, as teaching tool of business management students and executives, accomplishes and enriches conventional methods of teaching, such as lecturing, assigning of practical tasks, reading of specialty literature etc. Nevertheless, despite popularity of a case study method among prestigious Business Schools, various approaches to definition of a proper for teaching process case could be found, also different emphasizes on process of application of this teaching method have been put. The article deals with following issues: at first, characteristic features of case making it proper for teaching purposes have been considered; the second, detailed a case analysis' methodic, which enabled to increase efficiency of teaching process of business management in universities, has been presented. The methodic has been drawn up having objective more expressed orientation of teaching process to application of theoretical frameworks to solving real issues in specific business situations and development of concrete business decisions and also to form skills how to predict and evaluate plausible outcomes of alternative decisions. Practical application of a case study method let to accelerate acquisition of practical skills of students and make them better prepared for searching successful business decisions.
\end{abstract}

Keywords: a case study method, business decisions, business management studies, teaching tools and methods.

\section{Introduction}

Case teaching is amply used as a teaching tool at Harvard Business School, IESE Business School of University of Navarra and other Universities of a similar type. Putting emphasis on a case study and showing its coherency with education of future top managers, cases are in those business schools are considered as being the "first and foremost teaching vehicles" [1].

The article analyses case teaching in the following way. At first, the paper strives to present arguments letting to identify the business situation, which could be considered to be proper as "case" for teaching purposes.

The second, the article targets to outline the methodics of using case, which finally enabled to increase the efficiency of teaching business management students and professional business executives to develop or improve skills of generating business decisions, predicting then plausible outcomes and, hence, to increase the percentage of successful business decisions to issues which they encounter in their real activity.

\section{What business situation could be considered as proper "case"}

In case writing literature various definitions of proper or "good" case [1] could be found. The simplest, but the most felicitous description of case could be, e.g., as follows: case is a good story told by protagonist of business where crucial decision has to be made.

Natural question arises: if a "good" case always has to be a true story. What about the invention or simulation of a situation containing already programmed issue to be solved in a class? The simulation of situation could be supported by claim that a real situation is not always related strongly enough with theoretical framework; a lecturer would like to deliver within particular syllabus.

Should the case be a real situation or simulation depends on objectives of its application. If we pursue the aim to illustrate theory, of course, simulation serving as a practical exercise could serve perfectly.

Aiming to teach students or professionals to cope ef- 
ficiently with real problems, we naturally are forced to change our target of a teaching process. We need then to put emphasis not on the illustration of marketing concepts, which by themselves are inductive, but concentrate "on how the same set of relationships will play out in a different context" [1].

Considering our objective of teaching, which we stress, we support the approach which persists that "good" cases for teaching are real situations, but not simulations of problematic circumstances, in which a firm could occur. We believe that simulation, in principle, despite of abilities and experience of a simulator, hardly is able to reflect the complexity of reality. Even more, the more complex simulated situation is, the more it deviates from reality and eliminates such important opportunity for studying people as learning through experience. Simulating, simply, doesn't perform the role of sharing experience, reduce credibility of situation and diminishes excitement, which usually exists when real situations are analyzed and alternative decisions are discussed [2].

Another facet of the same question is that simulation hardly could enforce to suffer pain of decision-making, which is an undividable part of manager's performance and often leaves decision maker without a proper answer if alternative that was chosen has been the best. Simulation, on the contrary, usually lacks uncertainty, which is an unavoidable part of any business.

Hence, the first and the most important feature of proper case for teaching or "couching" [3] purposes is that business situation should be taken from real life. This lets to the taste complexity of choices and decisions, which theoretically sometimes could be treated as obvious or even as nonexistent.

The next requirement, which should be met in order to have a good case, is that management of a particular firm in the described situation would be forced to take action at this particular point of time. Proper case should provide the coherent description of relevant circumstances and inner or/and outer environment of a business firm. Real situation delivered by case should give enough clear understanding of the position of a firm and difficulties it encounters from the perspective of case protagonist. The next paramount characteristic of a business situation, which could be used successfully for teaching purposes, is clear description of circumstances. To put it in other way, only a rich context of situation from the point of view of protagonist allows another person to identify himself or herself with manager and simulate action. Only sufficient details allow the third person to percept as much fully as possible the real situation, in which not daily operational but important nonstandard decision from several possible alternatives has to be chosen, or even nontrivial alternatives invented.

Another essential question for those of us who have previously taught using conventional lecturing is what exact information, what content a good case should deliver to a reader. That delivered information has to be realistic and rich, we already discussed above.

Proper case can contain a vide range of information starting with human relationships, such as how to treat a good worker, which ignores work schedule and finishing with marketing or financial issues. A good case can contain any information, which is encountered in real business life and where a crucial decision has to be made. Hence a lecturer, who is going to use a case method as teaching technique, must choose a case or series of cases, which highlight relevant dimensions of the course he or she teaches. For instance, the course, which is taught, includes "break-even" point the lowest volume of product that firm can achieve and not to loose money. The proper case might present an issue of whether to build a new plant in order to introduce to market a new product. Such case enables a student to apply an analytical tool such as, analysis based upon fixed costs, revenues and variable costs, forcing him to grapple with the presented issue. Nevertheless, break-even analysis in our example doesn't provide the one "right" answer to the issue presented in case because it principally differs from practical exercise. Presented case describes a complex situation of business - all marketing questions of a new product in this case - hence performed break-even analysis, like in real life, serves only as one of techniques and arguments in the decision making process.

The distinction, which is important, regards the differences between a case and economical exercise used for teaching purposes, is the complexity of decision conditioned by the scale of interrelated uncertain factors. In our example related with building of a new plant and introducing a new product a series of uncertain factors such as plausible sales of a new product, which partly depends on plausible reaction of customers, competitors, our sales campaign and etc. On those uncertain sales we build our break-even analysis. That's the way business managers make vital decisions.

Considering the specific character of a case as realistic and complex reflection of a concrete business position from the perspective of its protagonist, the natural question arises: how to teach case if the application of a specific technique doesn't guarantee coming to a right decision, and what is the sense of teaching without providing precise recommendations to the problems, which certain business firm has encountered in the case. 


\section{A Case Study as the Shortest Way to Successful Business Decision}

A key to accepting a case study as a teaching method among other conventional methods, such as lectures, reading books, direct experience etc., is understanding what particular role it plays in a process of learning.

It is notorious, that the function of conventional methods of teaching is to deliver information to students, to make professional comments on it, to lead and structure a process of learning. The professional and pedagogical features of a lecturer in these activities are extremely important and necessity of such a process itself hardly could be questioned. Nevertheless, the application of theoretical models and theories in business field has its specific character and differs from the application of laws and theorems of sciences. In learning business management a mere act of learning of wise statements and sound advices does little for the preparation of a good manager. Business management is the field, in which the learner's dynamic cooperation is required. Such cooperation does not arise automatically; it has to be provided and continually encouraged [4].

The method is exactly the tool, which enables a student to put himself into the place of business protagonist and to generate actively decisions applying already earlier obtained theoretical knowledge. Considering an active role of a student we can treat the case a study method not as teaching method but as the method, which encourages learning or/and facilitates learning [5].

Having agreed on the place and mission of the case method in the process of learning we need to outline clearly strategic behavior of a lecturer, whose function is professionally to manage the process of learning.

Under the case system the instructor has to choose a case he wants to teach. Despite all the complexity of real situations reflected in cases, each lecturer has its specific field of interest, in which he has particular expertise. Hence, naturally he has to manage a class discussion in such a way that, on the one hand, to " facilitate the acquisition of habits of synthesis" [3] but, on the other hand, to facilitate learning of particular subject he teaches.

Putting emphasis on a particular subject - i.e. breakeven analysis - as in our example presented above, in some cases requires some "push" from side of an instructor. That is especially important in complex cases, which can be taught in different classes, in which other aspects of issue or even different issues can be stressed and analyzed more thoroughly.

Only successful pursuing of dual task - developing ability to synthesize and to apply the concrete knowledge of particular field - could lead to learning how to analyze various decisions and finally lay ground for the successful decision making in real business life.

The outline of a teaching process of a case plays the major role in achieving the most efficient results of learning. General approach to outlining the case teaching aims to encourage students to become active participants of a process of generating business decisions. Lecturer's task is to a lead discussion and to teach to analyze proposed business solutions.

Hence, the first step in a teaching process is the identification of a problem or problems. (I level of chart). Students are given freedom and stimulated to express their opinions about the problems a firm has encountered. A lecturer in the very beginning of an analysis of a case has to accept all the judgments expressed by students about possible "illness" of organization, which are based on the symptoms defined in a case. The aim of initiating the expression of various opinions is to develop qualities needed by business people, such as "the ability to see vividly the potential meanings and relationships of facts, both those facts having to do with persons and those having to do with things; capacity to make sound judgments on the basis of these perceptions; and skill in communicating their judgments to others" [4].

After possible problems have been defined, students are urged to propose decisions or, to put them into other way as a practical action scheme to solve the pointed out problems. Proposed decisions should be followed by the predicted most plausible results (as pointed out in II and III levels of chart). The function of a lecturer in this process is giving appropriate questions, comments, assigning role playing to students if the problem is connected with human relationships, to lead a student to see more clearly the possible outcome of the proposed by himself action plan. The more clear view of plausible outcome of the proposed action plan is an extremely important part of situation analysis and prerequisite of efficient business decision.

Students are encouraged to participate in the reevaluation of the proposed decision. That's the way business executive thinks: at first he or she generates a decision and then he analyzes if plausible results are satisfactory from his or her point of view. More clear view of possible outcomes has its own effect - some proposed decisions are seen as unacceptable and, number of proposed decisions is diminished to minimum.

Hence, the task of a lecturer in this process is to guide students through levels of decisions (II level in chart) and outcomes (III level in chart) and back to the revision of the proposed decisions. Feedback sent by the 


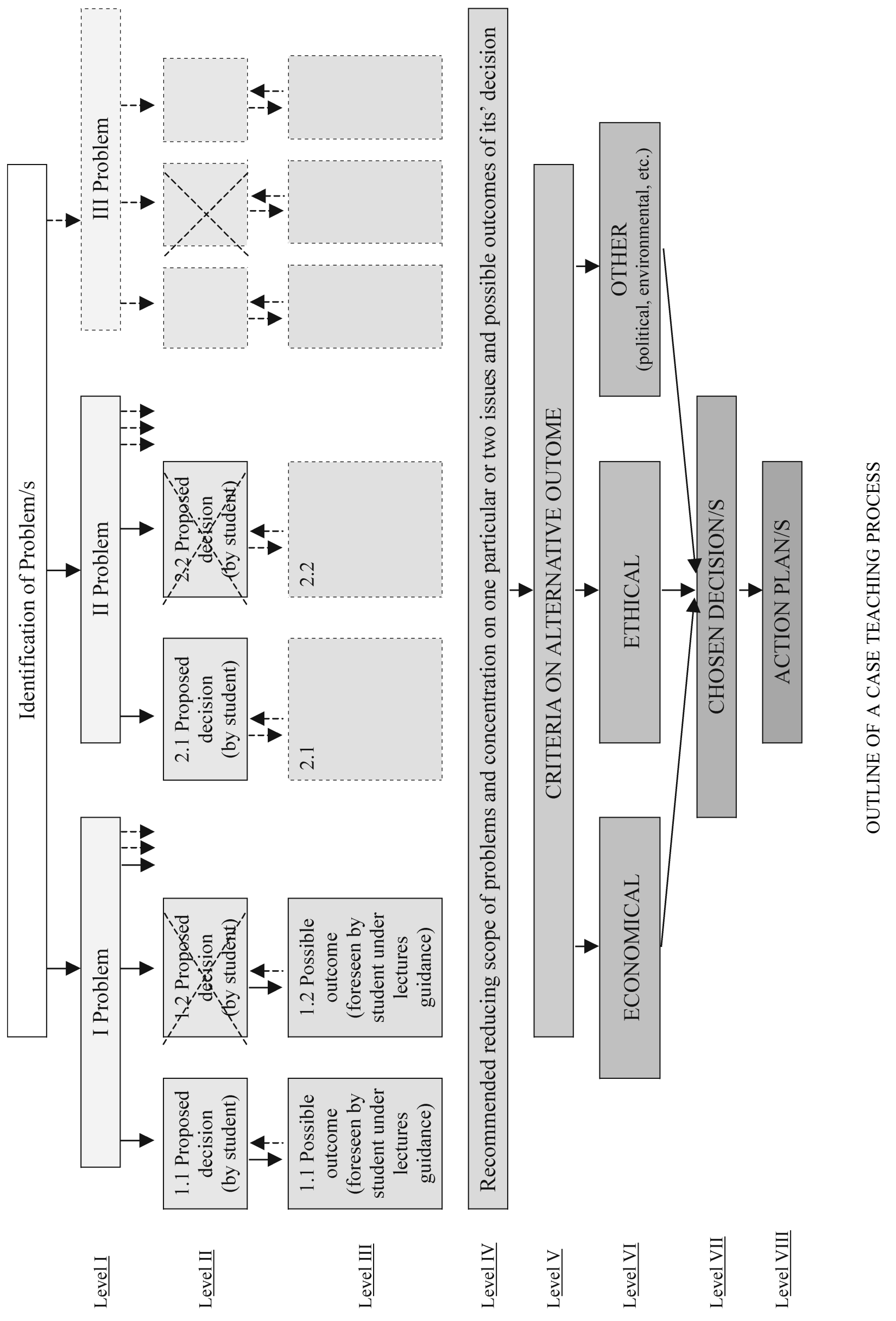


third level lets to concentrate on a smaller number of issues and decisions.

At this particular point prudential decision would be to emphasize one main issue and corresponding it action plans (IV level in chart). Putting emphasize on a certain problem lets the lecturer to employ his expertise and knowledge of students of a particular field. By this approach students have to be shown how general knowledge could be applied in a specific situation.

Having decided on which particular issues, action plans and outcomes to concentrate we need to turn to criteria. How to set criteria, then to range it according to its' importance and relevancy to general strategic and values of firm that is the matter of the next stage of a case analysis (VI level of chart).

In this particular point of a case analysis, as a rule, a question arises: which criterion should be accepted as the main and, which exactly action plan from the suggested set should be accepted. To put it in other way which decision is "right" (VII level of chart) considering other left decisions as "wrong".

A case discussion itself has a task to teach students to analyze business situations, to identify problems, to foresee possible action plans and to detect theirs the most plausible outcomes. This process repeated lots of times on the basis of vast array of different cases lets to practice to analyze situation-specific decisions, to group them and to trace their common features. As concerns "recipes" of action, it should be stressed, that they are not and can't be in principle the purpose of a case study.

Several reasons why a lecture should avoid giving categorical advices on action plan are as follows. The first, despite a case is the reflection of a real situation there could be always some confidential information, which a company wanted to disguise.

The next reason, which we need to keep in mind, is that a real situation could be much more complicated than in principle could be explored during a lecture.

The third reason, why giving "right" answers by the lecturer is unadvisable is based on notorious consideration that business deals with human behavior, where some laws or predetermined rules couldn't be blindly followed. Even good advise could trigger implausible, from the point of view of analyst, outcome.

Finally, we need to realize that "in every business situation, there is always a reasonable possibility that the best answer has not been found - even by the teachers [6].

One more moment, keeping in mind, which could prevent teachers from temptation to giving exact advises, is the difference between case and a piece of research.
At first, in a piece of scientific research, the "truth "is paramount. A case study tackles a different aim: learning to analyze and make grounded decisions is the main objective in a case study method.

\section{Conclusions}

A close look at the practice of using a case study method at IESE Business School of Navarra University in Barcelona and the study of appropriate materials have led to the following conclusions. Conventional teaching aimed to providing general business knowledge doesn't generate skills for the practical application of this knowledge. Hence, students after the graduation of university actually need to obtain some practical experience to be really able to make efficient business decisions.

A case study method lets to intensify a process of gaining experience analyzing a series of real business situations from the perspective of a business protagonist. This approach to a teaching process makes a case study method a powerful tool of teaching, which should be adopted in a contemporary business school. It should be used not instead, but together with conventional methods of teaching.

A teaching process of a case also requires specific management of a teaching process. The proposed scheme of teaching would condition the effective training of students through the contact with real business problems, accelerating the process of gaining experience and hence, couching them to make efficient business decisions in real life.

\section{References}

1. Roberts, M. J. (2001). Developing a Teaching Case, Harvard Business School, note 9-900-001: Harvard Business School Publishing.

2. Rangan V. K. (1996). Choreographing a Case Class Harvard Business School, note 9-595-074: Harvard Business School Publishing.

3. Vazquez-Dodero J. C., Ortiz E. (2001). The Case Method: The Instructor as "Choreographer", note 0-300089, IESE International Graduate School of Management, University of Navarra, Barcelona-Madrid: IESE Publishing

4. Gragg Ch. I. (1982). Becouse Wisdom Can't be Told. Harvard Business School, note 9-451-005: Business School Publishing.

5. Liuis G. Renart L. G. (2002). Presentation on Writing a good Case, IESE Business School, University of Navarra: IESE Publishing

6. Applegate L. M. (1995). Case Teaching at Harvard Business School: Some Advice for New Faculty, note 9-189062: Harvard Business School Publishing. 